\section{The first nanosecond}

Chlorophyll Organization and Energy Transfer in Photosynthesis. Ciba Foundation Symposium (new series). Edited by G. Wolstenholme and D. W. Fitzsimons. (Excerpta Medica: Amsterdam, Oxford and New York, 1979.) $\$ 38.25$; Dfl86.

THIS book presents the proceedings of a meeting held in February 1978, on the primary processes of photosynthesis. The events in question span the time from the moment when light is absorbed, to the first separation of electric charges. All this happens in less than a nanosecond $\left(10^{-9} \mathrm{~s}\right)$. The subsequent processes of biochemical electron transfer were deliberately excluded from consideration in this book. Those readers who find this too restrictive might consult Primary Processes of Photosynthesis (Topics in Photosynthesis, Vol. 2, edited by J. Barber; Elsevier: Amsterdam, New York and Oxford, 1977) which takes a broader view of the primary processes, at least as far as the millisecond time scale.

The present book is principally concerned with that remarkable molecule, chlorophyll and the way in which it is arranged in the chloroplast membranes to give the properties that are required for photosynthesis. In fact chlorophyll seems to exist in several types of proteolipid complex, each having a different function. The bulk of the chlorophyll serves as antenna to capture light energy and rapidly transfer it to reaction centres. The spectroscopic work of Katz and his group has convincingly shown that each reaction centre contains a special pair of chlorophyll molecules. The next step is presumed, by analogy with the simpler systems of photosynthetic bacteria, to be the formation of a radical pair in the reaction centre. From then onwards, the rest is chemistry. The details of these processes are being investigated from various directions. The structure of the system can be investigated by electron microscopy, and by biochemical investigation of the chlorophyll-protein complexes. The dynamics of energy transfer is investigated by spectroscopic techniques; at present only optical methods are fast enough. The most spectacular is laser-pulse spectroscopy which makes it posssible to study fluorescence lifetimes of the order of $10^{-11}-10^{-10} \mathrm{~s}$. 'Picosecond' has become something of a buzz-word in this field. By this means the initial processes of energy transfer are now accessible, if the results are compared with suitable chemical and/or theoretical models.

The papers are interspersed with long discussions, (which even have their own reference lists and index). These are one of the most valuable features of the book, for here the experts on these disparate methods are trying to reconcile their results to give a coherent picture. How can the chlorophyll-protein complexes extracted by Thornber, Anderson and others, be identified with the various lumps seen in the chloroplast membranes in the freeze-etch electron micrographs of Staehelin and Arntzen? How does the theory of exciton transfer allow energy to be transferred from them to the reaction centres? Perhaps there is more chlorophyll in between, and so on.

The view of the photosynthetic unit which this book takes as its starting-point is considerably more advanced than it was a few years ago. It is possible, as Sir George Porter suggests in his Chairman's introduction, that a fairly complete understanding may emerge in the next few years. We are not there yet, but the book gives an indication of the techniques by which this understanding may be achieved.

Richard Cammack

Richard Cammack is Lecturer in the Department of Plant Sciences, King's College, University of London, $U K$.

\section{Electrical}

\section{phenomena in polymeric materials}

Electrical Properties of Polymers. By A. R. Blythe. Pp.191. (Cambridge University Press: Cambridge, 1979.) £17.50.

THIS book provides an excellent basic introduction to a wide range of electrical phenomena in polymeric materials in terms of the molecular and electronic processes involved. It brings together the wellestablished area of dielectric relaxation, which has contributed greatly to our understanding of molecular conformations and correlated motions in polymers, with the less well understood phenomena of conduction and electrostatic charging, each of which are assuming increasing importance because of their relevance to polymer applications.

The introductory chapter includes a brief survey of the chemical and physical structure of polymers, providing a useful background to those with limited experience of polymer science. In chapter 2 the derivations of standard relationships between the equilibrium dielectric constant and molecular dipole moment are clearly outlined. The third chapter introduces and defines the frequency-dependent dielectric constants and discusses the associated relaxation parameters and underlying molecular reorientational processes. Chapter 4 presents a comprehensive account of dielectric measurement techniques. An illuminating discussion of current knowledge and ideas regarding ionic and electronic conduction mechanisms is given in chapter 5 together with relevant sections on conducting composites and resistivity measurements and some interesting suggestions on the feasibility of obtaining materials with novel conduction properties. The two final chapters are concerned with the practically important topics of dielectric breakdown and static charge phenomena, respectively.

The book is written with care and authority and is particularly recommended to students of polymer science as an educative text on electrical behaviour. Polymer research workers, industrial manufacturers and users of plastics should also find the book a useful acquisition, bearing in mind the detailed accounts of measurement techniques, the references to further reading at the end of each chapter and relevance of electrical properties to polymer applications.

B.E. Read

Bryan E. Read is in the Division of Materials Applications of the National Physical Laboratory, Teddington, UK.

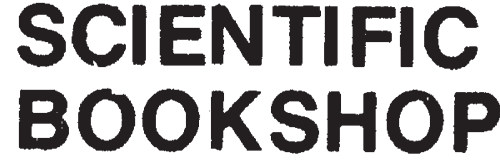

H. K. LEWIS can supply works in all branches of Pure and Applied Science. Catalogues on request. Please state interests.

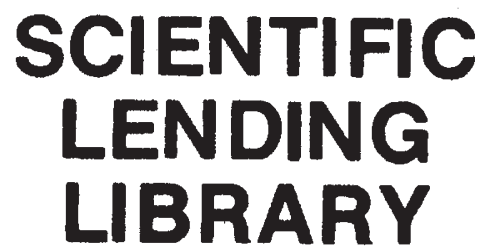

Annual Subacrlption from E7.50. (Available in U.K. only)

Reduced rates for multiple subscriptions.

Prospectus post tree on request.

Quarterly List of New Books and new editions added to the Library sent post free to subscribers regularly.

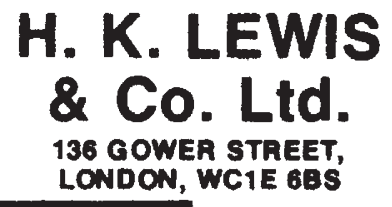

Telpphone: 01-387 4282

Tolograms: "Publlcavit,

London, wC1E 6BS."

Circle No. 09 on Reader Enquiry Card. 